\title{
Structural investigation of websites of selected educational hospitals of Shiraz University of Medical Sciences from Patient Relationship Management (PRM) perspective
}

\author{
Mahdieh Bakhshi ${ }^{1}$, Hossein Monem ${ }^{2}$, Omid Barati ${ }^{3}$, Roxana Sharifian ${ }^{4}$, Mohtaram Nematollahi ${ }^{5}$
}

${ }^{1}$ M.Sc. student, Department of Health Information Technology, School of Management and Medical Information Sciences, Shiraz University of Medical Sciences, Shiraz, Iran

${ }_{2}^{2}$ Assistant Professor, Department of Computer, School of Paramedical Sciences, Shiraz University of Medical Sciences, Shiraz, Iran

${ }^{3}$ Assistant Professor, Department of Health Services Management, School of Management and Medical Information Sciences, Shiraz University of Medical Sciences, Shiraz, Iran

${ }^{4}$ Associate Professor, Department of Health Information Management, School of Management and Medical Information Sciences, Health Human Resources Research Center, Shiraz University of Medical Sciences, Shiraz, Iran

${ }^{5}$ Associate Professor, Department of Health Information Management, Anesthesiology and Critical Care Research Center, Shiraz University of Medical Sciences, Shiraz, Iran

\section{Type of article: Original}

\begin{abstract}
Background: Hospital websites are considered as an appropriate system for exchanging information and establishing communication between patients, hospitals, and medical staff. Website character, website contact interactivity, shopping convenience, as well as care and service are the factors that the present study investigated as far as the patient relationship management is concerned.

Methods: This descriptive-analytical study was conducted on 206 patients visiting Shahid Faghihi and Ali Asghar Hospitals in Shiraz, which were capable of offering electronic services. The data collection tool was a researcher-made questionnaire based on the Mekkamol model and other similar studies, as well as investigations into the websites of the world's top hospitals. The questionnaire's validity was approved by a committee of experts and its reliability was approved based on a 54-patient sample with a Cronbach's alpha of 0.94. The data were analyzed using the Structural Equation Modeling (SEM) with partial least squares (PLS) approach and by utilizing SPSS and Smart-PLS V2 software programs.

Results: The results showed that there are significant relationships between "website character" and "website contact interactivity" $(\mathrm{p}=0.00)$, between "shopping convenience" and "website contact interactivity" ( $\mathrm{p}=0.00)$, and between "website contact interactivity" and "care and service" $(\mathrm{p}=0.00)$.

Conclusion: Website design with such characteristics as website simplicity, shopping convenience, authenticity of information, and provision of such services as admission, scheduling appointments, and electronic payment of bills will result in interaction and communication between patients and hospital websites. This will, for its turn, pave the way for attracting more patients.
\end{abstract}

Keywords: Patient Relationship Management, Hospital Website, Structural Equation Modeling

\section{Introduction}

In modern business environments, customers are considered as the focal point of all marketing activities. Customer relationship management (CRM) is the top priority for companies $(1,2)$. CRM is considered as a unified and potential marketing and information technology strategy to establish a profitable and long-term relationship with

\section{Corresponding author:}

Associate Professor Dr. Roxana Sharifian, Department of Health Information Management, School of Management and Medical Information Sciences, Health Human Resources Research Center, Shiraz University of Medical Sciences, Shiraz, Iran. Tel: +987132340774, Email: sharifianr@sums.ac.ir Received: January 02, 2016, Accepted: October 23, 2016, Published: July 2017 iThenticate screening: July 13, 2016, English editing: June 15, 2017, Quality control: June 16, 2017 (C) 2017 The Authors. This is an open access article under the terms of the Creative Commons Attribution-NonCommercialNoDerivs License, which permits use and distribution in any medium, provided the original work is properly cited, the use is non-commercial and no modifications or adaptations are made. 
customers and other key stakeholders. Therefore, CRM provides an opportunity to use data and information to understand customers and to create value with them (3). The need for CRM emerged when organizations understood that it was less costly to keep their current customers (4), while attracting a new customer would be five times more costly for an organization than keeping their current customers (5). In healthcare environments, patients are considered as the main customers; thus, the term Patient Relationship Management (PRM) is used in these contexts (6-8). PRM allows healthcare centers to have a better insight into the needs of patients while providing them with better care (7). In healthcare and treatment organizations, PRM focuses on such needs as determining the patients' appointments with physicians (8) and the history of the patients' treatments (9). If a patient is examined by a single physician every time he/she visits the center, because of the physician's familiarity with the patient, not only will the treatment process improve, but also the patient's time as well as the physician's time will be saved (9). In general, this system supports issues relating to the patient, information on the treatment, self-awareness, and the patient's care process (7). Based on existing statistical evidence, there were 2.4 billion Internet users worldwide in 2012 . With 42 million users, Iran has the highest number of Internet users among sixteen Middle East countries, ranking eighth in the world (10). These days, hospitals extensively use the Internet to provide their services (11). Patients can easily find instructions for their treatment via websites. When hospitals provide real information on the treatment of their patients through their websites, they will not only interact with patients but also help create a competitive environment with other hospitals when it comes to attracting patients (9). Websites have been designed to meet information needs and share necessary resources. Therefore, the design of websites should be based on the current needs of the users and should be flexible enough to meet their future needs so that it can enhance their level of satisfaction with the organization and gradually increase the organization's profitability in the long run (12). Findings of numerous studies have demonstrated that the websites of Iranian educational hospitals are average in terms of structure (main page, main links and sublinks), and very poor in terms of contents and sublinks (Themebased contents), needing modification, completion and expansion (13). Meanwhile, Shiraz is considered as the only developed metropolitan city in southern Iran with a high medical capacity, including well-known physicians, lowcost but high-quality medical services and the third rank in the world in organ transplantation (14). Thus, using the model presented by Mekkamol et al. (15), the present study investigates the structures of selected educational hospitals affiliated to Shiraz University of Medical Sciences from the perspective of PRM. This model consists of the following four constructs: "website character", "website contact interactivity", "shopping convenience", and "care and service". Considering the fact there have been very few studies already conducted to investigate the structure of hospital websites and PRM, we found it necessary to carry out such a research in healthcare organizations.

\section{Material and Methods}

This descriptive-analytical study was conducted in 2015. The statistical population in this study included all patients visiting Shahid Faghihi and Ali Asghar Educational Hospitals affiliated to Shiraz University of Medical Sciences. These hospitals were, at the time when the study was conducted, the only hospitals that provided their patients with electronic services. To determine the necessary sample size in the Partial Least Squares (PLS), the method proposed by Barclay et al. was used. According to this method, sample size is ten times more than the maximum number of existing relations of the structural model that are related to one variable (16). Since the maximum number of relations existing in the model has 19 variables, sample size in this study is determined to be 190 based on the above rule. Because of possible declines or failure to respond by respondents, $10 \%$ was added to the sample size. Thus, sample size was estimated to be 209 patients. Questionnaires were distributed among them. Finally, a total of 206 proper and complete questionnaires were returned and analyzed. To adhere to principles of ethics, the survey was conducted after receiving the patients' informed consent and promising them that their information would be kept confidential. The data collection tool in this study was a questionnaire that had been developed based on the relevant literature and the information relating to 20 websites of the world's top hospitals. To ensure the questionnaire's content validity, the views of professors and authorities in this field were used, and all necessary modifications were made. In this questionnaire, the five-point Likert scale was used and the Cronbach's alpha was used to assess its reliability. To this end, a prototype pre-test was conducted for 54 questionnaires and the Cronbach's alpha coefficient was 0.94. Data analysis was done using SPSS 19 and SMART PLSV2 software programs. In this study, Structural Equation Modeling (SEM) using partial least squares (PLS) was utilized to test the hypotheses and the model's goodness of fit. Using PLS, the validity of the model was evaluated in the following three sections: assessment of measurement models, structural model evaluation and overall evaluation of the model. To assess the reliability of the study's measurement model, the Cronbach's alpha and composite model (CM) as well as convergent validity (average variance extracted method and Fornell and Larcker's discriminant validity) were used. 
For the structural model, coefficients of $\mathrm{p}$-value and $\mathrm{R}^{2}$ criterion were used. At the end, the goodness of fit (GOF) benchmark test was used for the overall evaluation of the model.

\section{Results}

This study was conducted on 206 patients visiting selected hospitals in Shiraz. The sample population included 84 males (40.8\%) and 115 females (55\%). Among the respondents, 85 patients $(41.3 \%)$ were in the 18 to 30 age range, 64 patients $(31.1 \%)$ were in the 30 to 40 age range and 16 patients $(7.8 \%)$ were older than 40 years of age, while 106 patients $(51.5 \%)$ were married and 95 patients $(46.1 \%)$ were single. Meanwhile, 69 patients $(33.5 \%)$ of the sample population had their high school diploma, 96 patients $(46.6 \%)$ had their bachelor's degree, and 36 patients $(17.5 \%)$ had their master's or a higher degree. The Cronbach's alpha is considered as a classic criterion for assessing reliability and as an appropriate index for assessing internal consistency. A Cronbach's alpha higher than 0.7 indicates an acceptable level of reliability (17). The Cronbach's alphas of "care and service", "shopping convenience", "website character", and "website contact interactivity" were $0.766,0.930,0.844$, and 0.733 , respectively. Therefore, all the constructs of the structural model in this study had a desirable level of reliability. Composite reliability (CR) has been introduced by Werts et al (18). On this basis, the reliability of constructs is not absolute; rather, it is calculated based on the inter-correlation of their constructs. A CR value of higher than 0.7 for each construct (19) indicates an appropriate internal consistency of the measurement models, and a CR value of less than 0.6 indicates lack of reliability (20). The CR values of "care and service", "shopping convenience", "website character", and "website contact interactivity" were $0.880,0.938,0.879$, and 0.810 , respectively. Since the CR value for each construct was higher than 0.7 , the measurement model had an appropriate internal consistency. Fornell and Larcker introduced the average variance extracted (AVE) to assess convergent validity, stating that an AVE value higher than 0.5 shows an acceptable level of convergent validity (21). The AVE values of "care and service", "shopping convenience", "website character", and "website contact interactivity" were $0.71,0.66,0.69$, and 0.84 , respectively. Since the AVE values of the variables were higher than 0.5, the convergent validity of the measurement model was approved with a high level of confidence. As Table 1 shows, based on Fornell and Larcker's method, the root AVE values of the variables are in the cells in the main diameter of the matrix, which indicates that the correlation among them is higher in the lower left cells of the main diameter. Therefore, it can be argued that the model's constructs have a higher degree of interaction with their indexes than with other constructs. In other words, the divergent validity of the model is at an appropriate level. After assessing the validity and reliability of the measurement model, the determined structural model was assessed based on relations among nonobserved variables. Thus, the path coefficients and values of variance explained $\left(\mathrm{R}^{2}\right)$ for endogenous variables were examined. Chin proposed the three values of $0.19,0.33$, and 0.67 as the standard values for poor, average, and strong $\mathrm{R}^{2}$ values (22). In the PLS software, the goodness-of-fit of the model is achieved using the formula introduced by Tenenhaus et al. (23). Wetzels et al. introduced the three values $0.01,0.25$, and 0.01 as poor, average, and strong values. In other words, if the value of 0.01 , or a value close to it, is calculated as the GOF in a model, it can be concluded that the general fitness of the model is poor and the relations of the model's constructs should be modified. This also applies to the other two GOF values (24). Considering the achieved results, the hypotheses of the study were tested. The $\mathrm{R}^{2}$ values calculated for "care and service" and "website contact interactivity" constructs were 0.26 and 0.53 , respectively. Since the $\mathrm{R}^{2}$ values relating to these variables were higher than 0.19 , it was concluded that the structural model had a strong fitness. In addition, the value of fitness of the model in this study was 0.447 , indicating a highly appropriate fitness of the overall model. The criterion for assessing the relationship between the constructs in the model is the $\mathrm{p}$-value. A p-value of less than 0.05 shows proper relationship between the constructs and thus acceptance of the research hypotheses at the confidence interval of $95 \%$. Therefore, based on the findings of the study, there are significant relationships between "website character and "website contact interactivity" ( $p=0.00)$, between "shopping convenience" and "website contact interactivity" $(p=0.00)$, and between "website contact interactivity" and "care and service" $(\mathrm{p}=0.00)$.

Table 1. Construct correlation matrix

\begin{tabular}{|l|l|l|l|l|}
\hline Construct & Care and service & Shopping convenience & Website character & Website contact \\
\hline Care and service & 0.84 & & & \\
\hline Shopping convenience & 0.59 & 0.81 & & \\
\hline Website character & 0.59 & 0.79 & 0.83 & \\
\hline Website contact & 0.51 & 0.66 & 0.71 & 0.78 \\
\hline
\end{tabular}

\section{Discussion}

This study investigated the effect of "website character" on "website contact interactivity". The results showed that there is a significant relationship between these two constructs. Similarly, studies conducted by Mekkamol (15) and 
Feinberg (25) were compatible with the present study. The findings of the study by Nur Sukinah Aziz and those of the study by Stoica on "website characters" show that websites have in general, the following characters: feedback, resource utilization, attractiveness, likeability, flexibility, minimal memory load, operability, user guidance, consistency, self-descriptiveness, response time, loading time, completeness, readability, controllability, navigability, simplicity, familiarity, accuracy, and completeness of description (26 and 27). Approving the relationship between these two factors means that if a website is designed with a high degree of accuracy, based on specific principles, according to the above characteristics, and based on the needs of users, it will result in the establishment of interaction and communication between users and the website. "Shopping convenience" was another factor that was investigated in this study as far as its relationship with "website contact interactivity" is concerned. The results showed a significant relationship between "shopping convenience" and "website contact interactivity". The studies conducted by Mekkamol (15) and Sigala (28) revealed that "shopping convenience" is an effective factor in "website contact interactivity". "Shopping convenience" will promote customer services and online transactions. In addition, considering the fact that users become more experienced and their expectations rise with the passage of time, any problems in shopping behavior from the website will affect their support for the website and their trust in services (28). Therefore, if the process of receiving services via websites is done with more convenience, it will have a higher effect on the behavior of online buyers and thus will result in long-term relations with customers (patients) and interaction with the website. In this regard, electronic payment systems, admission before visiting the hospital, the possibility of changing appointments with an intended physician, etc. will lead to receiving services via the Internet, and this will be followed by an efficient and effective interaction between patients and the website. In this study, the relationship between "website contact interactivity" and "care and service" was also investigated. The results of this study revealed that there is a significant relationship between these two factors. Mekkamol (15) and Wolfinbarger (29) drew the conclusion that "website contact interactivity" and "care and service" are inter-related. Studies have shown that receiving information on the latest visits of the website by patients and the number of visits and use of the website, can be considered as factors that determine the degree of interaction with the website. However, professional design of the website, its capabilities, and the organization's reputation are effective factors in this area (30). Meanwhile, Ballantine has stated that the amount of presented information, the level of interaction with the website, as well as its characteristics and provided services have significant effects on user satisfaction (31). These factors will result in a more frequent use of the website by customers (patients) and their receiving services from the organization. Website content or information, convenience in receiving services, security, and satisfaction with the services provided by hospitals will create a competitive atmosphere in relation to other rivals when patients visit their website to receive services. The limitations of the study included the limited number of individuals using hospital websites as well as failure by some patients in the study to return their questionnaires. Nonetheless, the researchers tried to provide sufficient explanation for users of hospital websites in order to minimize the number of patients who failed to participate in the study. Despite these limitations, the present study is the first study, based on the results found by searching databanks of Iranian articles, which has provided basic information on the area of the structure and characteristics of hospital websites for healthcare policymakers.

\section{Conclusions}

The present study shows in brief that "website character" and "convenience in receiving facilities" have positive relationships with "website contact interactivity". This is while "website contact interactivity" will, for its turn, result in "patient satisfaction with the website" of hospitals. Therefore, website characters and services that can be provided for patients are considered as key factors in the design of websites. In addition, a simple design of a website with a language comprehensible to patients as well as convenience and speed of providing services, while considering their particular needs, will establish communication with patients, and increase their satisfaction. Therefore, it is suggested that provincial healthcare policymakers take into consideration adding electronic services for patients to hospital websites, including admission, scheduling appointments, and electronic payment of bills and thus provide CRM in a proper way. Through this process, they can not only save time and money but also attract more patients. Without a doubt, such a website will have a valuable role in providing better and quicker services for patients. In addition, it is recommended that an additional study be conducted to compare the websites of the country's top hospitals. Offering valuable solutions to improve the websites of the country's hospitals can be taken into consideration in the country's future research projects.

\section{Acknowledgments:}

The present article was adopted from Miss Bakhshi's MSc. thesis in Health Information Technology, Faculty of Management and Medical Information Sciences, Shiraz University of Medical Sciences, Shiraz, Iran. The authors 
would like to thank the Research Vice-Chancellor of Shiraz University of Medical Sciences for financially supporting the research (Contract No. 93-7279).

\section{Conflict of Interest:}

There is no conflict of interest to be declared.

\section{Authors' contributions:}

All authors contributed to this project and article equally. All authors read and approved the final manuscript.

\section{References:}

1) Zeithaml VA, Lemon KN, Rust RT. Driving customer equity: How customer lifetime value is reshaping corporate strategy. Simon and Schuster; 2001.

2) Karakostas B, Kardaras D, Papathanassiou E. The state of CRM adoption by the financial services in the UK: an empirical investigation. Information \& Management. 2005; 42(6): 853-63. doi: 10.1016/j.im.2004.08.006.

3) Payne A, Frow P. The role of multichannel integration in customer relationship management. Industrial marketing management. 2004; 33(6): 527-38. doi: 10.1016/j.indmarman.

4) Benanti J. The physician as customer. Health prog. 1988; 69(3): 62-5. PMID: 10286453.

5) Kotler P. Marketing Management: Analysis, Planning, Implementation and Control. New Yersey. PrenticeHall; 1994.

6) Monem H, Hussin A, Sharifian R. Comprehensive Prioritized Perspectives of CRM System for Implementation in the Developing Countries' Hospitals. International Journal of Computer Applications. 2012; 50(20): 5-12.

7) Oinas-Kukkonen H, Räisänen T, Hummastenniemi N. Patient relationship management: an overview and study of a follow-up system. J Healthc Inf Manag. 2007; 22(3): 24-9. PMID: 19267028.

8) Siau K. Health care informatics. IEEE Transactions on Information Technology in Biomedicine. 2003; 7(1): 1-7. doi: 10.1109/TITB.2002.805449.

9) Tan E, Untama JA, Weiershaus H, Raisinghani M. CRM Systems in German Hospitals: Illustrations of Issues \& Trends. IGI Global; 2005. doi: 10.4018/978-1-59140-673-0.ch004.

10) Salavati S, Hashim NH. Website adoption and performance by Iranian hotels. Tourism Management. 2015; 46: 367-74. doi: 10.1016/j.tourman.2014.07.017.

11) Patsioura F, Kitsiou S, Markos A. Evaluation of Greek Public Hospital Websites. ICE-B; 2009.

12) Choi B, Hong JW, Lee $C$, Lee H. Deriving web usage strategies for online sales: A decision framework and empirical exploration. Expert Systems with Applications. 2010; 37(5): 3695-705. doi: 10.1016/j.eswa.2009.11.057.

13) Moradi Gh, Ahmadi M, Zohoor A, Ebadifard Azar F, Saberi M. Evaluation of Structure and Content of Websites of the Educational Hospitals in Iran. Health Information Management. 2007; 4(2): 184.

14) Goodarzi M, Taghvaee M, Zangbaadi A. Investigation and evaluation of factors affecting the development of medical tourism in Shiraz. Tourism Management. 2013(23).

15) Mekkamol P, Piewdang S, Untachai S. Modeling e-CRM for Community Tourism in Upper Northeastern Thailand. Procedia-Social and Behavioral Sciences. 2013; 88(10): 108-17. doi: 10.1016/j.sbspro.2013.08.486.

16) Barclay D, Higgins C, Thompson R. The partial least squares (PLS) approach to causal modeling: Personal computer adoption and use as an illustration. Technology Studies. 1995; 2(2): 285-309.

17) Cronbach LJ. Coefficient alpha and the internal structure of tests. Psychometrika. 1951; 16(3): 297-334. doi: 10.1007/BF02310555.

18) Werts CE, Linn RL, Jöreskog KG. Intraclass reliability estimates: Testing structural assumptions. Educational and Psychological measurement. 1974; 34(1): 25-33. doi: 10.1177/001316447403400104.

19) Nunnally JC, Bernstein IH. Psychometric theory. New York: McGraw-Hill; 1978.

20) Nunnally JC, Bernstein IH, Berge JMt. Psychometric theory. New York: McGraw-Hill; 1967.

21) Fornell C, Larcker DF. Evaluating structural equation models with unobservable variables and measurement error. Journal of Marketing Research. 1981; 18(1): 39-50. doi: 10.2307/3151312.

22) Chin WW. Commentary: Issues and opinion on structural equation modeling. JSTOR; 1998.

23) Tenenhaus M, Amato S, Esposito Vinzi V, editors. A global goodness-of-fit index for PLS structural equation modelling. Proceedings of the XLII SIS scientific meeting. 2004: CLEUP Padova.

24) Wetzels M, Odekerken-Schröder G, Van Oppen C. Using PLS path modeling for assessing hierarchical construct models: Guidelines and empirical illustration. MIS quarterly. 2009; 33(1): 177-95. 
25) Feinberg RA, Kadam R, Hokama L, Kim I. The state of electronic customer relationship management in retailing. International Journal of Retail \& Distribution Management. 2002; 30(10): 470-81. doi: $10.1108 / 09590550210445344$.

26) Aziz NS, Kamaludin A, Sulaiman N. Assessing web site usability measurement. International Journal of Research in Engineering and Technology. 2013; 2(9): 386-92. doi: 10.15623/ijret.2013.0209058.

27) Stoica I, Orzan G, Dobrescu A, Radu AC. Online Marketing Communication Using Websites. A Case Study of Website Utility in Accessing European Funds in the Tourism Field Regarding Northeastern Romania. Procedia Economics and Finance. 2015; 23: 926-35. doi: 10.1016/S2212-5671(15)00436-0.

28) Sigala M. Culture: the software of e - customer relationship management. Journal of Marketing Communications. 2006; 12(3): 203-23. doi: 10.1080/13527260600811787.

29) Wolfinbarger M, Gilly MC. eTailQ: dimensionalizing, measuring and predicting etail quality. Journal of retailing. 2003; 79(3): 183-98. doi: 10.1016/S0022-4359(03)00034-4.

30) Jarvenpaa SL, Tractinsky N, Saarinen L. Consumer trust in an internet store: a cross - cultural validation. Journal of Computer - Mediated Communication. 1999; 5(2): 0. doi: 10.1111/j.1083-6101.1999.tb00337.x.

31) Ballantine PW. Effects of interactivity and product information on consumer satisfaction in an online retail setting. International Journal of Retail \& Distribution Management. 2005; 33(6): 461-71. doi: $10.1108 / 09590550510600870$. 